\title{
A educação integral no mais educação: uma análise do programa
}

Full time education in the "programa mais educação": an analysis

\author{
Camila Aparecida Pio* \\ Universidade Estadual de Londrina \\ Eliane Cleide da Silva Czernisz** \\ Universidade Estadual de Londrina
}

Resumo O texto analisa o Programa Mais Educação e tem como objetivo discutir a proposta de Educação Integral no referido Programa, implantado no Governo Lula. A proposta deste Programa e a forma como a Educação Integral é nele contemplada são questionadas neste estudo que se utiliza de pesquisa e discussão bibliográfica, análise de documentos. O Programa Mais Educação desenvolve-se como ação do Plano de Desenvolvimento da Educação e a Educação Integral é reforçada como meta do Plano Nacional de Educação. Como resultados, verifica-se que, no primeiro Governo Lula, a educação é apresentada como meta de inclusão social e, no segundo mandato, a meta do desenvolvimento do país a partir da educação de qualidade. Mostra-se que a Educação Integral implementada corresponde à ampliação do tempo de permanência do aluno na escola.

Palavras-chave: Educação, Políticas Educacionais, Programa Mais Educação.

Abstract This text analyzes "Programa Mais Educação" (More Education Program), with the objective to discuss the integral education proposal of the referred program, implemented by the Lula government. The Program's proposal and the way Full Time Education is contemplated are questioned in this study through a research, bibliography review, analysis of documents. It was verified that the Programa Mais Educação is part of the Plano Nacional de Educação (National Education Plan), in which full time education is stressed as the current Program's goal. Results showed that during Lula's first term in government, education is presented as a social inclusion target and in his second term, the country's development plan was based on quality education. They also showed that integral education, included expanding student's presence in the school environment.

KEYWORDS: Education, Education Policies, Programa Mais Educação. 


\section{Introdução}

No campo educacional, a busca por uma educação pública que atenda aos anseios da sociedade tornou-se assunto central nas discussões governamentais, nas esferas federal, estaduais e municipais. Com esta intenção, muitos programas educacionais têm sido lançados e com as mais diferentes propostas, ora para ensinar os conteúdos científicos historicamente acumulados pela humanidade, ora para formar o cidadão trabalhador e, assim, promover a inclusão social. Dentre os programas recentemente implementados, pode-se destacar o Programa Mais Educação, lançado nos primeiros anos do segundo mandato do presidente Luiz Inácio Lula da Silva (2002/ 2006, 2007/2010), como proposta de fomento à Educação Integral de Crianças, Jovens e Adolescentes. As considerações iniciadas neste texto têm como objetivo discutir a proposta de Educação Integral no Programa Mais Educação, inaugurado pelo Governo Lula. Questiona-se: Qual a proposta do Programa Mais Educação do Governo Lula? Como a Educação Integral é contemplada no referido Programa?

Este estudo compõe pesquisa de Mestrado em Educação, que se encontra em andamento. O trabalho, que se utiliza de pesquisa e discussão bibliográfica, está sendo realizado com base em análise de documentos de políticas e de documentos de governo, como: os Programas de Governo Lula (2002 e 2007), o Plano de Desenvolvimento da Educação (2007), O Programa Mais Educação (2007) e outros referentes à sua implementação na esfera federal. Segundo Shiroma, Campos e Garcia (2005, p. 440), a análise de documentos possibilita compreender as vinculações políticas e as intenções que estão nas entrelinhas de um programa, ou de uma legislação, haja vista que as políticas educacionais são "[...] ao mesmo tempo, texto, prática discursiva e prática social [...]”. As autoras também explicitam que os documentos de políticas são produzidos em um determinado momento e com um dado objetivo, e que sua implantação ocorre, muitas vezes, em contextos e espaços diferenciados dos quais foram pensados, daí a necessidade de se realizar uma análise cautelosa das políticas, essencialmente educacionais. Guiado por este referencial que embasa a análise de documentos, este trabalho se organiza em duas partes. Na primeira, discute-se a proposta de Educação, engendrada no Governo Lula, com base no estudo dos Programas de Governo (2002 e 2007); na segunda, discorre-se sobre a proposta de Educação Integral implementada por meio do Programa Mais Educação no Governo Lula. Finalmente, são tecidos alguns apontamentos sobre a proposta de Educação Integral do Programa Mais Educação.

\section{O Governo Lula e a proposta de Educação}

Como a análise da proposta para a Educação, desenvolvida no Governo Lula, não pode ser realizada isoladamente, é necessário retomar-se o contexto de sua constituição. O presidente Lula venceu as eleições de 2002, iniciando seu primeiro mandato em 2003, após oito anos de governo do presidente Fernando Henrique Cardoso (FHC), período marcado por diversas reformas econômicas, como a privatização de empresas estatais, o controle inflacional e a busca por estabilidade econômica. Cumpre lembrar que estas ações se deram num cenário de considerável aumento da desigualdade social. No campo educacional, as reformas podem ser discutidas a partir 
de Silva Júnior (2002, p. 100), que afirma que muitas das mudanças propostas - por exemplo, a reforma da Educação Superior e do Ensino Médio - "[...] são parte do movimento de reforma educacional no Brasil - na condição de dimensão orgânica das reformas educacionais de todo o mundo -, bem como decorrência da reforma do Estado [...]". Para o autor, essa reforma direciona tanto o Ensino Superior quanto o Ensino Médio como uma estratégia de adaptação à nova demanda de acumulação do capital, com ênfase na formação de um sujeito eficaz e competente para garantir a "[...] excelência do privado e do mercado" (SILVA JÚNIOR, 2002, p. 66).

A Reforma do Estado foi fundamentada no Plano Diretor da Reforma do Aparelho do Estado, aprovado em 1995, com o objetivo de superar a administração pública patrimonialista e burocrática, passando para uma administração pública gerencial que possibilitaria maior eficiência e flexibilização de serviços públicos. Verificase que tal mudança sofreu influência dos ideais do "Consenso de Washington", expressão cunhada em 1990 pelo economista John Williamson que, segundo Fiori (2001, p. 84), traduz as "[...] políticas econômicas defendidas unanimemente pelas principais burocracias econômicas norte-americanas e pelos organismos multinacionais sediados na cidade de Washington", cujo principal objetivo era a reestruturação econômica dos países latino-americanos. Sob esta lógica, a Reforma pretendeu promover a eficiência e a qualidade na prestação de serviços, tendo como foco a redução de custos. Embora estas discussões sejam latentes da década de 1990, seus ideais assolam as atuais políticas.

Nesse aspecto, é ilustrativo o primeiro Programa do Governo Lula, divulgado em 2002, composto por metas e objetivos a serem cumpridos durante o mandato 2003/2006. Neste primeiro documento, intitulado "Um Brasil para Todos: Crescimento, Emprego e Inclusão Social”, logo no título, evidencia-se a preocupação do presidente Lula com questões relativas à inclusão social e ao desenvolvimento econômico. Curiosamente, neste primeiro Programa de Governo, a Educação é discutida no contexto da inclusão social, justificada pela ênfase na articulação do desenvolvimento social e econômico, que, segundo o documento, "[...] fundamenta-se nos princípios éticos e nas prescrições constitucionais relacionados com o direito à vida, à dignidade da pessoa humana e à justiça social e com compromissos cívicos e patrióticos" (BRASIL, 2002, p. 39).

Neste sentido, o Governo Lula considera a Educação como recurso de promoção da cidadania e, sobretudo, como "[...] instrumento fundamental para o desenvolvimento e a inserção competitiva de qualquer nação no mundo" (BRASIL, 2002, p. 45). Entende-se que o objetivo da educação, neste contexto, articula-se com os ideais econômicos, aspecto que perpassa toda a discussão do Programa do Governo Lula. Fundamentalmente, para a proposta educacional, o Programa do Governo Lula (2002) parte de críticas do projeto educacional do Governo FHC (descentralização executiva, insuficiência de recursos, privatização do atendimento, essencialmente nos cursos superiores) e afirma:

[...] é preciso investir eficientemente no ensino, ampliando o acesso das crianças à escola. É vital recuperar a rede pública, tanto no ní- 
vel fundamental quanto no médio e nas universidades, valorizando principalmente a qualidade. Uma boa formação da juventude colabora para a retomada do desenvolvimento sustentável, além de ser um diferencial para a competição do País no mercado internacional. A educação de qualidade é fator de emancipação e cidadania, contribui para que os jovens se integrem ao mercado de trabalho e evita a fragmentação social que alimenta a violência e o crime organizado (BRASIL, 2002, p. 15).

Percebe-se que tal defesa vislumbra uma preocupação com a formação do cidadão e do trabalhador, aspectos que explicitam, pela análise deste Programa de Governo, uma educação pragmática e uma provável amenização da exclusão social, possibilitando o crescimento do mercado, contribuindo para o crescimento econômico do país.

Para compreender a proposta de educação no Governo Lula, também é relevante analisá-la no Programa de Governo do seu segundo mandato (2007/2010). O Programa de Governo (BRASIL, 2007, p. 5), logo no início, apresenta a mensagem: "O nome do meu segundo mandato será desenvolvimento. Desenvolvimento com distribuição de renda e educação de qualidade". Isso evidencia que a discussão sobre uma educação de qualidade constitui-se um dos temas centrais do Governo Lula, associada ao desenvolvimento econômico e à distribuição de renda. É possível destacar que a bandeira deste Programa de Governo continuou sendo a ampliação das políticas sociais para o combate à exclusão, à pobreza e à desigualdade, motivo que o levou a efetivar políticas assistencialistas, por meio de programas que somente apaziguaram os problemas emergentes da exclusão, como, por exemplo, o Bolsa-Família, considerado um dos maiores programas para redução da pobreza, mas que, fundamentalmente, ajuda parcialmente as famílias em pobreza extrema, não gerando empregos ou condições dignas de sobrevivência.

Será dada ênfase ao acesso à escola pública democrática e de qualidade; à superação do analfabetismo, à inclusão digital, ao acesso mais amplo à educação profissional, técnica e tecnológica, e a uma universidade reformada, expandida e de qualidade superior. Por serem pressupostos e também fatores fundamentais para garantir a inclusão econômica, social e politica de dezenas de milhóes de brasileiras e brasileiros, esse compromisso assumirá o caráter de objetivo estratégico do segundo governo Lula. Trata- se, portanto, de conceber a educação como questão nacional de primeira grandeza e torná-la prioridade do Estado e da sociedade (BRASIL, 2007, p. 12) - Grifo nosso.

O segundo mandato do Governo Lula é marcado pela fertilidade de programas educacionais, a saber: o Programa Universidade para Todos - PROUNI, o Programa Nacional de Acesso ao Ensino Técnico e Emprego - PRONATEC e outros. A educação continua aqui sendo reafirmada como condição para a inserção de milhões de pessoas no processo econômico, social e político, o que contribui para a inserção do país na economia mundial.

Logo no primeiro ano do segundo mandato do Governo Lula, é perceptível a promulgação de vários documentos que subsidiam a implantação de programas edu- 
cacionais, os quais podem ser comprovados via promulgação do Decreto n. 6.094/2007, que dispõe sobre o Plano de Metas Compromisso Todos pela Educação, e com o lançamento do Plano de Desenvolvimento da Educação (PDE), no ano de 2007. A ampliação do número de programas e ações educacionais também está presente no Plano Plurianual (PPA) 2008/2011, e é justificada devido ao fato da educação constituir-se como "[...] um objetivo estratégico sem o qual o projeto de desenvolvimento nacional em curso não se viabiliza" (BRASIL, 2007, p. 16).

O Plano de Metas Compromisso Todos pela Educação (BRASIL, 2007) é um documento composto por 28 diretrizes, que visam à melhoria da educação básica e prevem articulação entre os entes federados (União, Distrito Federal, Estados e Municípios) e sua atuação em regime de colaboração com as famílias e a comunidade para o cumprimento das metas propostas. Em linhas gerais, o Plano de Metas foi de grande percepção do Governo Federal, na medida em que forja a constituição da escola "democrática", por meio do envolvimento de todos na educação, e, ao mesmo tempo, se isenta parcialmente da sua responsabilidade de oferta de educação pública e gratuita para todos.

Neste mesmo período, é lançado o PDE, por meio do documento "O Plano de Desenvolvimento da Educação: razões, princípios e programas” (2007, p. 6) que afirma que este:

[...] pretende ser mais do que a tradução instrumental do Plano Nacional de Educação (PNE), o qual, em certa medida, apresenta um bom diagnóstico dos problemas educacionais, mas deixa em aberto a questão das ações a serem tomadas para a melhoria da qualidade da educação. É bem verdade, como se verá em detalhe a seguir, que o PDE também pode ser apresentado como plano executivo, como conjunto de programas que visam dar consequência às metas quantitativas estabelecidas naquele diploma legal, mas os enlaces conceituais propostos tornam evidente que não se trata, quanto à qualidade, de uma execução marcada pela neutralidade. (BRASIL, 2007, p. 6).

Como pode ser verificado nesta citação, o PDE é composto por um conjunto de programas educacionais, os quais devem ser desenvolvidos pelas instituições escolares, objetivando a busca da qualidade educacional. Embora, na citação, o PDE tenha sido referenciado como 'plano executivo', verifica-se, na discussão de Saviani (2009, p. 30), que este não se configura como um plano executivo, ou como um plano de educação, ele é "[...] antes, um programa de ação", dentre as quais encontra-se o Programa Mais Educação. Em sua origem, o PDE foi apresentado com trinta ações, distribuídas em quatro eixos: Educação Básica, Alfabetização e Educação Continuada, Ensino Profissional e Tecnológico e Ensino Superior. Segundo Saviani (2009, p. 5), os programas educacionais vão sendo criados e agregados ao $\mathrm{PDE}$, que se caracteriza "[...] como um grande guarda-chuva que abriga praticamente todos os programas em desenvolvimento pelo MEC".

Discutindo especificamente o Programa Mais Educação, como proposta de fomento à Educação Integral, cabe ressaltar que, embora ele tenha sido lançado em 
2007, a proposta de Educação Integral já era prevista no artigo 34 da Lei de Diretrizes e Bases da Educação Nacional n. 9394/96 com a possibilidade de progressiva ampliação do tempo de permanência dos alunos na escola e no Plano Nacional de Educação (PNE) 2001/2010, reafirmada na Lei n. 13.005/2014, que aprova o novo Plano Nacional de Educação 2014/2024.

O PNE 2001/2010 afirmava a educação de tempo integral como uma estratégia para garantir às crianças das camadas sociais desprivilegiadas a formação mínima exigida na sociedade moderna. Um trecho deste plano explicita o argumento:

\begin{abstract}
A oferta qualitativa deverá, em decorrência, regularizar os percursos escolares, permitindo que crianças e adolescentes permaneçam na escola o tempo necessário para concluir este nível de ensino, eliminando mais celeremente o analfabetismo e elevando gradativamente a escolaridade da população brasileira. A ampliação da jornada escolar para turno integral tem dado bons resultados. $\mathrm{O}$ atendimento em tempo integral, oportunizando orientação no cumprimento dos deveres escolares, prática de esportes, desenvolvimento de atividades artísticas e alimentação adequada, no mínimo em duas refeições, é um avanço significativo para diminuir as desigualdades sociais e ampliar democraticamente as oportunidades de aprendizagem. (BRASIL/PNE, 2001, p. 23).
\end{abstract}

O Programa Mais Educação pode ser entendido como afirmação e sequência da proposta de escola de tempo integral, apresentada neste plano, uma vez que a busca pela qualidade educacional se limita à ampliação do tempo de atendimento aos alunos, estratégia que contribui para a diminuição da desigualdade social.

Representando um avanço em relação ao PNE 2001/2010, o PNE 2014/2024 apresenta uma meta específica que trata da oferta da Educação Integral: "Oferecer educação em tempo integral em, no mínimo, 50\% (cinquenta por cento) das escolas públicas, de forma a atender, pelo menos, $25 \%$ (vinte e cinco por cento) dos (as) alunos (as) da educação básica" (BRASIL, 2014, p. 3). Para cumprimento desta meta, são apresentadas nove estratégias que tratam desde a organização estrutural até a organização pedagógica das instituições de tempo integral, que são aquelas cujos alunos permanecem, no mínimo, sete horas diárias sob responsabilidade da escola durante todo o período letivo. É perceptível, no novo Plano Nacional de Educação, que a proposta de Educação Integral segue as discussões do Programa Mais Educação já em curso, caminhando no sentido de: ampliação do tempo de permanência dos alunos na escola, desenvolvimento de atividades "extracurriculares", articulação com outros espaços que não a escola, entre outros.

É sob este pano de fundo que a Educação e a Educação Integral foi pensada e implementada no Governo Lula e continua sendo desenvolvida no Governo Dilma Rousseff 2011/2014: educação entendida como fundamental no combate à exclusão e a desigualdade e na redução da pobreza, tripé que está intrinsecamente ligado ao desenvolvimento econômico do país, e sua inserção na economia internacional, pressuposto presente no Governo FHC e perpetuado ainda hoje. 


\section{O Programa Mais Educação e seus desdobramentos}

O Programa Mais Educação, lançado pela Portaria Normativa Interministerial n. 17/2007, incluso no PDE como um programa do eixo "Educação Básica", teve como objetivo fomentar a educação integral entre crianças, adolescentes e jovens, e pode ser apontado como a proposta de Educação Integral do Governo Lula e Dilma.

Sob uma análise geral, esta sugestão de Educação Integral apresenta-se como um programa meramente executivo, que reduz a concepção de Educação Integral à ampliação do tempo de permanência do aluno na instituição escolar, concepção visível no Decreto n. 7.083/2010, que dispõe sobre o Programa Mais Educação:

Art. $1^{\circ}$ O Programa Mais Educação tem por finalidade contribuir para a melhoria da aprendizagem por meio da ampliação do tempo de permanência de crianças, adolescentes e jovens matriculados em escola pública, mediante oferta de educação básica em tempo integral.

$\S 1^{\circ}$ Para os fins deste Decreto, considera-se educação básica em tempo integral a jornada escolar com duração igual ou superior a sete horas diárias, durante todo o período letivo, compreendendo o tempo total em que o aluno permanece na escola ou em atividades escolares em outros espaços educacionais.

$\S 2^{\circ}$ A jornada escolar diária será ampliada com o desenvolvimento das atividades de acompanhamento pedagógico, experimentação e investigação científica, cultura e artes, esporte e lazer, cultura digital, educação econômica, comunicação e uso de mídias, meio ambiente, direitos humanos, práticas de prevenção aos agravos à saúde, promoção da saúde e da alimentação saudável, entre outras atividades.

$\S 3^{\circ}$ As atividades poderão ser desenvolvidas dentro do espaço escolar, de acordo com a disponibilidade da escola, ou fora dele sob orientação pedagógica da escola, mediante o uso dos equipamentos públicos e do estabelecimento de parcerias com órgãos ou instituições locais. (BRASIL, 2010, p. 1).

Neste artigo, várias questões podem ser discutidas. A primeira é a ênfase dada ao desenvolvimento da Educação Integral por meio da ampliação do tempo de permanência do aluno na escola, concepção reafirmada no parágrafo primeiro, que define a educação básica em tempo integral como a jornada letiva igual ou superior a sete horas diárias. A segunda questão - as atividades a serem desenvolvidas durante o tempo de permanência dos alunos na escola - são descritas no parágrafo segundo, que apresenta uma gama delas a serem implementadas, como: ampliação do acompanhamento pedagógico, experimentação e investigação científica, que requer profissionais formados e espaços propícios para isso, no caso, a escola, e não outros espaços como sugerido no parágrafo terceiro. Esta é uma relação problemática, haja vista que exime do Estado a responsabilidade de garantir a estrutura física para instituições escolares, essencialmente para o alargamento do tempo de permanência escolar, no qual a criança e o adolescente necessitam de condições efetivas: banheiro adequado, sala de refeições, entre outros. 
Quando se discute Educação Integral nessa pesquisa, toma-se a concepção de Saviani (2007), segundo a qual, seria a formação do homem em sua totalidade, em todas as múltiplas dimensões: intelectual, física e social; e a concepção gramsciana (1985) de escola unitária, que é a proposição de uma escola única para os filhos dos trabalhadores e para os filhos da burguesia, por meio da qual, todos podem ter acesso aos conteúdos acumulados e sistematizados pela humanidade. No entanto, o que se evidencia, na proposta de Educação Integral do governo Lula, é a ampliação do tempo de permanência do aluno na escola para acolher os filhos dos trabalhadores e atender as crianças que se encontram em vulnerabilidade social. Não existe uma discussão conceitual para esta proposta, apenas a adesão de muitas instituições, exclusivamente aquelas que se encontram em regiões mais vulneráveis. Tanto é esta a realidade, que o programa não visa atender a totalidade das instituições escolares, mas, essencialmente, aquelas que se enquadram nos critérios de adesão ao programa.

Em 2013, foi lançado, pelo Ministério da Educação (MEC), em parceria com a Secretaria de Educação Básica (SEB), e pela Diretoria de Currículos e Educação Integral (DCEI), o "Manual Operacional de Educação Integral” (2013), que define os critérios de adesão e funcionamento do programa. Dentre os referidos critérios, os que mais chamam atenção são: "[...] escolas que possuam o IDEB abaixo ou igual a 3,5 nos anos iniciais e/ou finais, IDEB anos iniciais < 4.6 e IDEB anos finais < 3.9. [...] Escolas com índices igual ou superior a 50\% de estudantes participantes do Programa Bolsa Família" (BRASIL, 2013, p. 21).

Cumpre esclarecer que o Índice de Desenvolvimento da Educação Básica (IDEB) é um mecanismo de acompanhamento e avaliação da qualidade educacional, por meio da aprovação e média de desempenho dos estudantes em língua portuguesa e matemática, obtidos pelo Censo Escolar, e médias de desempenho nas avaliações do Inep (Instituto Nacional de Estudos e Pesquisas Educacionais Anísio Teixeira), o Saeb (Sistema de Avaliação da Educação Básica) e a Prova Brasil. O IDEB já é um aspecto que deve ser discutido criticamente por se constituir uma análise quantitativa de educação e, quando se torna, juntamente com o aspecto que envolve o Bolsa-Família, critério de adesão ao Programa Mais Educação, reafirma-o como um programa, cujo objetivo é atender escolas que se encontram em bairros periféricos e de vulnerabilidade social, ou seja, um programa especificamente direcionado para os filhos da classe trabalhadora.

Quanto ao aspecto formativo, este programa traz uma proposta com possibilidade questionável de execução por propor atividades de difícil exequibilidade, tanto em termos de estrutura física quanto de financiamento, haja vista que grande parte das instituições escolares dispõe de poucas salas de aulas e nem todas contam com quadras poliesportivas ou bibliotecas.

As atividades propostas se dividem nos seguintes macrocampos: Acompanhamento pedagógico; Comunicação, uso de mídias e cultura digital e tecnológica; Cultura, artes e educação patrimonial; Educação ambiental, desenvolvimento sustentável e economia solidária e criativa/ educação econômica; e Esporte e lazer. Em sua execução, depara-se com outro encaminhamento problemático deste programa: a re- 
afirmação do trabalho de monitoria a ser realizado "[...] por estudantes universitários de formação específica nas áreas de desenvolvimento das atividades ou pessoas da comunidade com habilidades apropriadas [...]" (BRASIL, 2013, p. 23). Neste aspecto, novamente, evidencia-se a desresponsabilização do Estado em relação à contratação de profissionais formados para atuarem com os alunos, colocando em questionamento a educação de qualidade almejada, reduzindo os gastos com a educação e privando os alunos de terem aulas com professores formados e capacitados.

Mesmo com estas lacunas, muitas escolas estão ampliando o tempo de permanência dos alunos, e pesquisadores têm debatido sobre seus limites e possibilidades. Dentre algumas pesquisas, destaca-se: "A escola de tempo integral: a implantação do projeto de uma escola no interior paulista” (CASTRO, 2009), que discute a implementação de escolas de tempo integral no Estado de São Paulo, especificamente da Diretoria de Ensino da Região de Pirassununga, buscando apontar os limites e possibilidades desta implantação. Também debatendo a proposta de escola de tempo integral do Estado de São Paulo, há a análise de Dib (2010), "O programa de Escola de Tempo Integral na região de Assis: implicações para a qualidade do ensino”, que analisa as Escolas de Tempo Integral da Diretoria de Ensino da Região de Assis e aponta a relação entre a ampliação do tempo de permanência dos alunos na escola e a melhoria no processo de aprendizagem. Nas discussões do cenário paranaense, destaca-se Ferreira (2007), com o trabalho "Escola em tempo integral: possível solução ou mito na busca da qualidade?”, que enfoca a análise da implementação das escolas públicas de tempo integral no município de Apucarana - Paraná e, assim como o trabalho de Dib, estabelece sua relação com a melhoria da qualidade do ensino. No cenário mineiro, ressalta-se o estudo "Implantação da escola em tempo integral, no município de Juiz de Fora/MG: trajetória e perspectivas”, de Silva (2009), que discorre a respeito da implantação e efetivação da escola de tempo integral no município de Juiz de Fora - Minas Gerais, apontando para a necessidade de um diálogo crítico entre os gestores escolares sobre o projeto. Vale destacar que estas pesquisas não discutem especificamente o Programa Mais Educação, mas projetos de diferentes estados e municípios que propuseram a implementação de escolas integrais, e que, assim como o Programa Mais Educação, se configuram com a ampliação do tempo de permanência dos alunos na instituição escolar.

Efetivamente, na discussão do Programa Mais Educação, destaca-se Silva (2013), com a tese "Interesses, Dilemas e a Implementação do Programa Mais Educação no município de Maricá (RJ)”, que discute a implementação do referido Programa no município de Maricá, no Rio de Janeiro, e apresenta depoimentos de diretores, professores, voluntários, pais de alunos e alunas, que se mostram favoráveis ao Mais Educação nas escolas, por ser um programa de atividades prazerosas. No entanto, Silva (2013) se posiciona contrário à visão consensual de que o Programa Mais Educação se configura como um instrumento de efetivação de uma educação de qualidade, afirmando:

Não se trata de negar a possibilidade de que, em alguns casos, o programa esteja propiciando melhorias localizadas e fazendo diferença na vida de crianças e jovens que frequentam as escolas públicas por 
ele contempladas. A chegada de mais recursos sempre pode possibilitar melhorias mas, se junto com esses recursos chegam também situações deletérias ao curso da democratização da educação pública, torna-se difícil considerá-las como avanços. As condições gerais em que se processa a implementação do programa são precárias e acabam dependendo, muito mais, da "boa vontade" dos sujeitos envolvidos e das circunstâncias locais das escolas do que da ação efetiva do poder público, seja ele federal, estadual ou municipal. (SILVA, 2013, p. 239).

As considerações da pesquisa empírica realizada por Silva, no município de Maricá, reafirmam algumas lacunas já evidenciadas na análise documental do Programa Mais Educação, como a falta de espaço físico e de recursos para o desenvolvimento das atividades, falta de profissionais formados e capacitados para atuarem, ausência de discussões conceituais sobre a proposta de "Educação Integral", falta de uma organização curricular que contemple a ampliação de atividades a serem desenvolvidas de acordo com a especificidade da educação escolar.

Estes são alguns dos desdobramentos do Programa Mais Educação, evidenciados no decorrer deste estudo, que explicita a proposta de Educação Integral, evidenciando que muito ainda há que ser pesquisado.

\section{Alguns apontamentos}

$\mathrm{Na}$ expectativa de tecer algumas considerações, reafirma-se a concepção de Educação Integral como aquela que visa ao desenvolvimento do educando em sua totalidade intelectual, física e social, por meio do ensino dos conteúdos historicamente produzidos, acumulados e sistematizados pela humanidade. Tomando esta concepção como norteadora de uma proposta emancipadora de educação, o que fica patente no Governo Lula é uma proposta educacional que se diz preocupada com a qualidade educacional, com a formação crítica dos educandos, mas que, na verdade, as considera o motor do desenvolvimento econômico do país, buscando desenvolver programas educacionais para amenizar problemas sociais, como a vulnerabilidade social, a fome, o analfabetismo, a formação técnica, entre outros. Estes aspectos podem ser evidenciados nos dois Programas de Governo Lula (2002 e 2007), na ênfase ao combate à desigualdade e à exclusão social, condição para o desenvolvimento econômico do país, e, também, na proposta de Educação Integral deste governo, implementada por meio do Programa Mais Educação.

O Programa Mais Educação pode ser caracterizado como um programa passível de questionamentos, uma vez que a simples ampliação do tempo de permanência dos alunos na escola, o atendimento a instituições escolares de baixo IDEB, com alunos integrantes do Programa Bolsa-Família, apontam um programa de caráter mais assistencialista do que educacional. É questionável quanto à sua exequibilidade, por propor o desenvolvimento de uma gama de atividades de esporte, lazer e cultura, o que exigiria a reestruturação física das instituições escolares e um alto investimento na aquisição de materiais e contratação de profissionais formados, que quase nenhuma instituição possui. E é assistencialista, porque prevê o atendimento à escolas periféri- 
cas e a permanência de crianças, adolescentes e jovens, em período integral na escola, como estratégia de redução da vulnerabilidade social, uma vez que estariam seguras e receberiam alimentação adequada.

Com estes apontamentos que não esgotam a temática, evidencia-se a necessidade de conceituação do que se entende por Educação Integral, uma vez que, no Programa Mais Educação, esta tem se caracterizado como ampliação do tempo de permanência dos alunos na escola a partir da expansão da jornada, que requer, simplesmente, a diversificação das atividades escolares em desenvolvimento, ou a adição de atividades "extracurriculares" para preencher o tempo em que os alunos permanecem na instituição.

\section{Referências}

BRASIL. Câmara da Reforma do Estado. Plano Diretor da Reforma do Aparelho do Estado. 1995. Disponível em: <http://www.bresserpereira.org.br/Documents/MARE/PlanoDiretor/ planodiretor.pdf $>$. Acesso em: 5 set. 2013.

. Decreto $n^{\circ}$ 6.094, de 24 de Abril de 2007. Dispõe sobre a implementação do Plano de Metas Compromisso Todos pela Educação, pela União Federal, em regime de colaboração com Municípios, Distrito Federal e Estados, e a participação das famílias e da comunidade, mediante programas e ações de assistência técnica e financeira, visando a mobilização social pela melhoria da qualidade da educação básica. Diário Oficial da União. República Federativa do Brasil - Imprensa Nacional. Brasília - DF, 25 abr. 2007, Seção 1. Disponível em: <http://www.planalto.gov. br/ccivil_03/_ato2007-2010/2007/decreto/d6094.htm>. Acesso em: 31 jan. 2014.

. Decreto no 7.083, de 27 de Janeiro de 2010. Dispõe sobre o Programa Mais Educação. Diário Oficial da União. República Federativa do Brasil - Imprensa Nacional. Brasília - DF, 28 jan. 2010, Edição Extra, Seção 1. Disponível em: <http://www.planalto.gov.br/ ccivil_03/_ ato2007-2010/2010/decreto/d7083.htm>. Acesso em: 31 jan. 2014. BRASIL.

Lei $n^{\circ}$ 13.005, de 25 de junho de 2014. Aprova o Plano Nacional de Educação - PNE e dá outras providências. Diário Oficial da União. República Federativa do Brasil - Imprensa Nacional. Brasília - DF, 26 jun. 2014, Edição extra, Seção 1. Disponível em: <http://www.jusbrasil.com.br/diarios/72231505/dou-edicao-extra-secao-1-26-06-2014-pg-3/pdfView>. Acesso em: 5 jul. 2014.

Lula presidente: Programa de Governo 2007/2010. Disponível em: <http://www. fpabramo.org.br/uploads/Programa_de_governo_2007-2010.pdf>. Acesso em: 2 ago. 2013.

Ministério da Educação. Lei n 9.394, de 20 de dezembro de 1996. Estabelece as diretrizes e bases da educação nacional. Brasília, DF. Disponível em: <http://portal.mec.gov.br/ arquivos/pdf/ldb.pdf>. Acesso em: 28 jan. 2014.

. Ministério da Educação. Manual Operacional de Educação Integral. Brasília: MEC/ SEB/DCEI, 2013. Disponível em: <Erro! A referência de hiperlink não é válida.>. Acesso em: 7 fev. 2014.

Ministério da Educação. O Plano de Desenvolvimento da Educação: razões, princípios e programas. Brasília, DF. Disponível em: <http://portal.mec.gov.br/arquivos/livro/>. Acesso em: 11 set. 2013.

Ministério da Educação. Plano Nacional de Educação. Lei no 10.172/2001. Brasília, DF: MEC, 2001. Disponível em: <http://www.planalto.gov.br/ccivil_03/leis/leis_2001/110172. htm>. Acesso em: 19 jan. 2014. 
BRASIL. Ministério da Educação. Portaria normativa interministerial no ${ }^{\circ}$ 17, de 24 de abril de 2007. Institui o Programa Mais Educação, que visa fomentar a educação integral de crianças, adolescentes e jovens, por meio do apoio a atividades sócio-educativas no contraturno escolar. Brasil: MEC, 2007. Disponível em: <http://portal.mec.gov.br/index.php?option=com_docman\&task=doc_http://portal.mec.gov.br/index.php?option=com_docman\&task=doc_\%20 download\&gid\%20=2446\&Itemid=download\&gid =2446\&Itemid=>. Acesso em: 30 abr. 2013.

. Ministério do Planejamento, Orçamento e Gestão. Secretaria de Planejamento e Investimentos Estratégicos. Desenvolvimento com Inclusão Social e Educação de Qualidade: Plano Plurianual 2008/2011. Brasília, 2007. Disponível em: <http://www.planejamento.gov. br/secretarias/upload/Arquivos/spi/plano_plurianual/PPA/081015_PPA_2008_mesPres.pdf>. Acesso em: 17 dez. 2013.

Programa de Governo - Lula 2002. 2002. Disponível em: <http://www1.uol.com.br/ fernandorodrigues/arquivos/eleicoes02/plano2002-lula.doc>. Acesso em: 2 ago. 2013

FIORI, J. L. 60 lições dos 90: uma década de neoliberalismo. Rio de Janeiro: Record, 2001.

CASTRO, A. A Escola de Tempo Integral: a implantação do projeto em uma escola do interior paulista. 2009. Tese (Doutorado em Educação) - UFSCAR, São Carlos, 2009.

DIB, M. A. B. O programa Escola de Tempo Integral na região de Assis: implicações para a qualidade do ensino. 2010. Tese (Doutorado em Educação)- UNESP, São Paulo, 2010.

FERREIRA, C. M. P. S. Escola em tempo integral: possível solução ou mito na busca da qualidade? 2007. Dissertação (Mestrado em Educação) - UEL, Londrina, 2007.

GRAMSCI, A. Os intelectuais e a organização da cultura. Rio de Janeiro: Civilização Brasileira, 1985, Parte II, p. 117-157.

SAVIANI, D. PDE - Plano de Desenvolvimento da Educação: análise crítica da política do MEC. Campinas: Autores Associados, 2009.

D. Trabalho e educação: fundamentos ontológicos e históricos. Revista Brasileira de Educação, v. 12, n. 34, p. 152-1880, jan./abr. 2007. Disponível em: <http://www.scielo.br/pdf/ rbedu/v12n34/a12v1234.pdf>. Acesso em: 29 mar. 2014.

SHIROMA, E. O.; CAMPOS, R. F.; GARCIA, R. M. C. Decifrar textos para compreender a política: subsídios teórico-metodológicos para análise de documentos. Perspectiva, Florianópolis, v. 23, n. 02, p. 427-446, jul.-dez. 2005. Disponível em: <http://www.ced.ufsc.br/nucleos/ nup/perspectiva.html.>. Acesso em: 28 jul. 2013.

SILVA, B. A. R. Interesses, Dilemas e a Implementação do Programa Mais Educação no município de Maricá (RJ). 2013. Tese (Doutorado em Educação) - UFRJ, Rio de Janeiro, 2013.

SILVA, E. M. L. Implantação da escola em tempo integral no município de Juiz de Fora/ MG: trajetórias e perspectivas. 2009. Dissertação (Mestrado em Educação) - UNIRIO, Rio de Janeiro, 2009.

SILVA JÚNIOR, J. R. Reforma do Estado e da Educação no Brasil de FHC. São Paulo: Xamã, 2002.

* Mestranda da Universidade Estadual de Londrina, Londrina, Paraná, Brasil.

** Professora Doutora da Universidade Estadual de Londrina, Londrina, Paraná, Brasil. 


\section{Correspondência}

Eliane Cleide da Silva Czernisz - Universidade Estadual de Londrina, Centro de Educação Comunicação e Artes, Departamento de Educação. Rodovia Celso Garcia Cid (PR-445), km 369 Campus Universitário. CEP: 86051-990, Londrina, Paraná, Brasil.

E-mail: elianecleide@gmail.com

Recebido em 05 de agosto de 2014

Aprovado em 18 de setembro de 2014 
